\title{
O estudo de biografias nas aulas de espanhol: uma proposta de trabalho
}

Natalia Labella-Sánchez*

Resumo: Este relato de experiência objetiva socializar as atividades desenvolvidas nas aulas de língua espanhola com turmas de $8^{a}$ série de ensino fundamental, ao longo de um trimestre. $\mathrm{O}$ ponto de partida para o processo de ensino e aprendizagem foi o estudo de biografias em língua espanhola. As biografias foram estudadas e utilizadas em sala de aula com o objetivo de que os estudantes ampliassem o seu conhecimento de mundo, realizassem pesquisas, compartilhassem conhecimentos e elaborassem uma tarefa final demonstrando os resultados da aprendizagem e das reflexões acerca do gênero. Para essa tarefa final, contei com a colaboração dos professores e professoras de Artes que acrescentaram muito à atividade por meio da troca de ideias, sugestóes e conhecimentos mais específicos.

Palavras-chave: Ensino de espanhol, Gênero de texto, Biografias.

Abstract: This experience description aims at sharing the activities that took place during Spanish classes with students of the $8^{\text {th }}$ grade of elementary school throughout a trimester. The teaching and learning had biographies in Spanish as a starting point. The biographies were used and studied in the classroom so that they would enable students to widen their knowledge of the world, do research,

Mestre em Estudos da Linguagem pela Universidade Estadual de Londrina. Professora de Língua Espanhola do ensino fundamental e da educação de jovens e adultos do Colégio de Aplicação da UFRGS. E-mail: natalia.labella@yahoo.com.br 
share knowledge and produce a final task. For this final task, I had the help of Art teachers who contributed to the activity by sharing ideas, suggestions and expertise.

Keywords: Spanish teaching, Text genre, Biographies.

Trabalhar biografias na sala de aula pode tomar diferentes dimensões, dependendo dos objetivos que o professor queira alcançar com seus alunos. Ler e escrever biografias pode, por exemplo, ser uma forma de os alunos se tornarem capazes de resumir informações. Contudo, trabalhar com esse gênero de texto também pode abrir um caminho amplo e diversificado de contato com novas informaçóes e novos conhecimentos, principalmente se as atividades propostas não forem somente de exploração superficial do texto.

Objetivando relatar a experiência de ensino e aprendizagem de língua espanhola por meio do estudo de biografias, entendo que é importante descrever o meu ambiente de trabalho, contextualizando melhor o espaço em que acontecem as aulas e como elas se organizam.

Atualmente, trabalho no Colégio de Aplicação (CAp) da Universidade Federal do Rio Grande do Sul (UFRGS) e parte de minha atribuição docente é junto a duas turmas de $8^{a}$ série. A maioria dos alunos estuda no CAp há vários anos e tem duas aulas semanais de língua espanhola desde a $5^{\text {a }}$ série. Nas séries iniciais, o CAp também oferece contato com essa língua através de oficinas oferecidas anualmente. Como alguns alunos entraram na escola recentemente, é bastante comum os conhecimentos de espanhol serem heterogêneos, já que parte dos alunos nunca havia estudado espanhol antes. ${ }^{1}$ Além disso, as turmas de língua estrangeira são sempre divididas entre mais professores, fazendo com que os grupos tenham no máximo 18 alunos.

Esses alunos, bem como outros que apresentem dificuldades em sala de aula, têm a sua disposição um encontro semanal de reforço nos chamados Laboratórios de Ensino. 
Outra característica do ensino de espanhol no CAp é que não utilizamos livros didáticos em nossas aulas e, portanto, são os professores que elaboram o material didático, de acordo com o que planejam trabalhar. É outra prática do Colégio desenvolver, sempre que possível, os conteúdos de forma integrada com mais de uma disciplina, ou seja, de modo interdisciplinar. As trocas de ideias a este respeito ocorrem nas chamadas "reuniões de série", nas quais todos os professores e professoras podem compartilhar com os colegas os conteúdos que estão sendo abordados nas aulas. Geralmente, é a partir dessa socialização de conteúdos que surgem as ideias de trabalhos associados entre duas ou mais disciplinas.

Inserida nesse contexto de ensino, no início do $1^{\circ}$ trimestre de 2008, houve troca de sugestões entre os professores e professoras das $8^{\text {as }}$ séries. Minha ideia inicial era trabalhar biografias com os alunos, dentro de um projeto que levaria esse mesmo nome, "Biografias". Como tarefa final, os alunos teriam que apresentar uma biografia de artistas espanhóis ou hispanoamericanos (pintores, muralistas, arquitetos, escultores). Antes de levar a ideia ao grupo, eu já havia falado previamente com a professora de Artes Visuais ${ }^{2}$ sobre a proposta, de forma que a turma pudesse dar um encaminhamento menos superficial para a realização da tarefa final.

\section{Organizando as atividades para o trimestre}

Quando decidi envolver os alunos num trabalho com biografias, já comecei a pensar em como isso poderia ser organizado e desenvolvido. Para viabilizar a realização de uma série de

2 Ao longo do trimestre, os alunos das $8^{\text {as }}$ séries tiveram mais de um professor de Artes Visuais devido à licença-maternidade de uma das colegas e ao teste seletivo para contratação de novos docentes. Apesar da troca de professores, o intercâmbio de sugestôes foi mantido. 
atividades ao longo de um trimestre, é fundamental o estabelecimento de objetivos, o planejamento prévio do desenvolvimento semanal das aulas e a organização do material a ser utilizado. Segundo Alonso (1999), o sucesso de uma proposta de ensino depende também do planejamento de um objetivo principal, definindo o eixo orientador das atividades desenvolvidas em sala. Isso torna mais fácil a realização de adaptações necessárias ao longo do processo, dando mais segurança ao professor e coerências às aulas.

$\mathrm{Na}$ tentativa de estabelecer e definir quais eram meus objetivos e como desenvolveria as atividades, decidi me basear no trabalho com gêneros textuais utilizando os pressupostos teóricos do Interacionismo Sociodiscursivo (ISD). Os seus pesquisadores defendem que

(...) para que os objetivos de ensino-aprendizagem em torno de gêneros possam ser atingidos, as práticas escolares de produção e compreensão textual devem ser norteadas pelo que chamam de modelos didáticos de gênero a ser ensinado [...]. A construção desse modelo de gênero permitiria a visualização das dimensões constitutivas do gênero e seleção das que podem ser ensinadas e das que são necessárias para um determinado nível de ensino. (MACHADO, 2007, p. VII)

Para Bronckart (2003), todo gênero de texto apresenta elementos característicos que os definem como tal. Seguindo a proposta de análise do ISD, era importante eu organizar meu planejamento com base em atividades que permitissem desenvolver as capacidades de linguagem (SCHNEUWLY; DOLZ, 2004) dos alunos por meio do estudo das biografias. Para isso, era necessário: a) explorar as características que envolvem a situação de produção de textos biográficos (quem escreve, para quem escreve, quem são os possíveis leitores, quais são os seus interesses, em que suportes a biografia circula, com que objetivos, tipo de linguagem utilizado); b) observar os conteúdos típicos desse gênero; c) observar como o seu conteúdo se organiza e como a linguagem é articulada. 
Outro desafio que precisou ser enfrentado quando selecionei o gênero biografia dizia respeito ao fato de que

(...) todas as biografias [...] possuem características similares. Elas são constituídas de textos pouco densos e linguisticamente menos complexos, pois revelam apenas aspectos básicos e fundamentais da vida dos biografados, como nome, data de nascimentos, profissão/atuação, alguns fatos a respeito da trajetória profissional e, quando falecidos, local, data e motivo da morte, etc. (ALONSO; CRISTOVÃO, 2007, p. 180) (grifo nosso)

Diante disso, precisavam ser elaboradas atividades que não se resumissem em copiar, em espanhol, biografias já existentes ou atividades que não tornassem a leitura desses textos objeto único de análise linguística e ensino de aspectos gramaticais ou lexicais da língua espanhola. Isso porque, perante um texto considerado "pouco denso", é muito tentador querer explorar apenas os aspectos linguísticos mais presentes nas biografias: verbos no pretérito indefinido, pretérito imperfecto e pretérito perfecto compuesto (quando o biografado ainda está vivo), o uso correto da estrutura utilizada para empregar datas em espanhol, sem falar dos números que aparecem constantemente nas biografias. Certamente o trabalho com esses elementos ocorreria em algum momento, mas a minha proposta não era tornar isso o centro do trabalho.

\section{Como trabalhar as biografias, então?}

Considerando previamente os aspectos expostos até agora, decidi que os estudos de biografias teriam que estar associados integralmente ao acesso a novos conhecimentos e levar os alunos a relacionarem os biografados a suas obras. Desse modo, organizei um material que tornasse os textos biográficos um ponto de partida para os alunos conhecerem ou (re)conhecerem as produções dos biografados. Além disso, o material também objetivou explorar e/ou confirmar os conhecimentos prévios dos alunos sobre o que conheciam das características desse gênero, já que a tarefa final era a produção de uma biografia. 
Na primeira parte do material, procurei explorar ao máximo os conhecimentos prévios dos alunos com relação às biografias. Para isso, formulei perguntas (todas em espanhol, aqui traduzidas) como: a) Certamente você já leu alguma biografia. Cite as fontes onde você já as leu ou onde elas podem ser publicadas. b) Para que serve uma biografia?; c) Que tamanho pode ter um texto biográfico; d) Escreva o nome de pessoas sobre quem você já tenha lido uma biografia.

A partir das respostas dadas pelos alunos, todas essas questôes foram discutidas em sala de aula. Ao longo das discussões, eles mostraram conhecer vários aspectos relacionados ao gênero, mas demoraram para perceber que biografias não são lidas somente em sala de aula e por obrigação, como eles apontaram. Embora tenham citado diversos suportes onde as biografias podem ser publicadas, incluindo revistas voltadas para um público adolescente, eles não associavam a leitura de biografias de cantores(as) ou atores e atrizes conhecidos a esse meio de publicação, por exemplo. Instiguei-os um pouco mais a esse respeito e, logo em seguida, eles começaram a citar uma lista imensa de pessoas biografadas. Isso mostra que, por mais óbvio que algumas características que fazem parte desse gênero possam parecer (como o lugar onde circulam esses textos), por vezes, os alunos não têm consciência disso.

Na segunda parte do material, selecionei biografias de diferentes personalidades espanholas e hispano-americanas, todas relacionadas com a literatura: Federico García Lorca, Isabel Allende, Maria Elena Walsh, Pablo Neruda, Mario Vargas Llosa, Julio Cortazar, José Julián Martí Perez, Gabriel García Márquez. A escolha foi proposital, já que a literatura é algo que aparece muitas vezes alheia às aulas de língua estrangeira. Paralelo ao recebimento desse material, também entreguei uma outra folha com textos produzidos pelos biografados ou que tivessem alguma relação com eles.

Sempre que possível, escolhi textos que eles reconhecessem, de alguma maneira, e que a leitura dos mesmos também 
causasse aquela sensação de "eu conheço esse texto, mas a quem será que pertence?”. Notei, pelos comentários dos alunos, que vários deles passaram por essa experiência. Eles conseguiram associar a poesia Mammelita à autora María Elena Walsh, já que eles tinham aprendido a cantar a música nas séries iniciais do CAp e visto o filme que leva esse mesmo nome.

Além disso, todos conheciam a música Guantanamera, mas não sabiam - até então - quem a tinha composto e por que (essas informações apareciam na biografia de José Martí). Coloquei a árvore genealógica da Familia de los Buendia, de Cem Anos de Solidão, e como alguns alunos sabiam quem era García Márquez, acabaram passando a informação para os demais colegas. Também selecionei a letra Go Back, cantada pelo grupo brasileiro Titãs, já que a letra é baseada/inspirada numa poesia de Pablo Neruda (Farewell y Sollosos). Também selecionei entrevistas e curiosidades dos demais biografados.

Essa segunda parte proporcionou momentos de forte interação entre os alunos e uma motivação para descobrir a quem pertenciam os textos. Nesse momento da proposta, eles tiveram que ler todas as biografias para relacionarem os textos aos seus respectivos autores. Os alunos o fizeram de forma bastante entretida e com um objetivo que ia além de ler corretamente as palavras e/ou os números em espanhol.

Também organizei atividades de produção de biografia entre os próprios alunos. Pedi que eles recortassem no mínimo dez palavras que representassem fatos ou questões importantes em suas vidas e colocassem em envelopes não identificados. Esse material foi redistribuído entre os colegas e pedi que escrevessem textos biográficos com as informações que tinham. Alguns conseguiram identificar os colegas biografados, outros não. Isso também foi objeto de reflexão junto aos alunos: isso significava que o "biógrafo" não conhecia bem o seu "biografado" ou que o "biografado" não havia selecionado as palavras certas? Esse simples exercício os fez concluir outra característica da biografia: ela sempre é escrita/produzida após muita pesquisa. 


\section{Realização da tarefa final: pesquisando e produzindo biografias de artistas espanhóis e hispano-americanos}

Como a tarefa final do trimestre envolvia a pesquisa de biografia de artistas, em aulas anteriores, trabalhei com o grupo um texto biográfico sobre a pintora mexicana Frida Kahlo. Vários alunos já haviam estudado algo a seu respeito no ano anterior. Mesmo aqueles alunos que não a conheciam, tiveram acesso a ela, por meio da leitura de seu texto biográfico. Nesse texto, destacava-se o sofrimento pelo qual ela passara ao longo de toda a sua vida, após um terrível acidente que sofrera quando ainda era jovem.

Entretanto, o que mais interessava-me não era tanto os fatos chocantes da vida dela, mas sim explorar com os alunos como esses fatos poderiam influenciar em sua arte, já que essa artista específica tinha se autorretratado em diferentes quadros ao longo de toda a sua vida. Não é exagero dizer que Frida Kahlo revela muito de seus sentimentos e sofrimentos físicos e psicológicos através de seus quadros, e "escreve" a sua autobiografia a pinceladas e por meio de pequenos textos que ela escrevia em algumas de suas telas.

Para a realização da tarefa final do trimestre, dividi os alunos em duplas ou trios e fiz o sorteio dos artistas espanhóis e hispano-americanos que seriam foco de suas pesquisa. A lista havia sido compartilhada com os professores de Artes e, sempre que possível, eles procuravam utilizar características desses artistas em suas aulas. O sorteio incluía os seguintes nomes: a) artistas espanhóis: Pablo Picasso, Velázquez, Gaudí, Salvador Dalí, El Greco, Goya, Miró; b) artistas hispano-americanos: Torres García, Diego Rivera, Siqueiros, Botero, Orozco. 
As pesquisas foram realizadas na internet. Nas duas visitas que os alunos fizeram ao laboratório de informática, eles utilizaram o site de busca google e foram incentivados a utilizar o google da Espanha ou a colocar a preferência de pesquisa em língua espanhola. O objetivo era que eles conseguissem informações sobre as personalidades que deveriam biografar e também selecionar imagens de obras importantes do artista de sua responsabilidade.

Nesse ponto surgiram duas novas questões. A primeira estava relacionada à forma como os alunos selecionariam e organizariam as informações obtidas nas páginas da internet. A segunda, tinha relação com a preocupação de que a apresentação final não se reduzisse à leitura de dados biográficos resumidos de textos da internet, sem que os alunos realizassem reflexão alguma sobre a produção artística do biografado.

Essa última preocupação foi novamente compartilhada com os professores de Artes e eles sugeriram que além das pesquisas biográficas e de seleção das obras, os alunos também realizassem uma leitura das obras escolhidas. A princípio, essa leitura poderia ser feita através de uma pintura, desenho ou até mesmo escultura, mas depois optei por uma leitura representada por palavras em espanhol que revelassem as impressốes que as obras causaram nos alunos.

Propus que eles organizassem as apresentações com o auxílio de cartazes, nos quais deveria constar uma breve biografia do artista, as obras escolhidas pelo grupo e as palavras que comporiam a leitura das obras. Cada aluno deveria escolher uma obra diferente para que todos tivessem a oportunidade de refletir sobre ela e pudessem explicar para os colegas no dia das apresentações orais. 

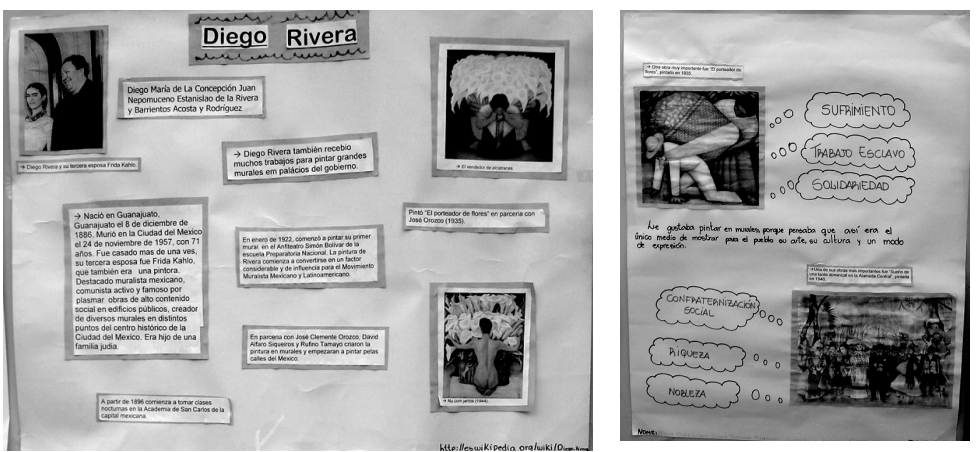

Fig. 1 - Cartazes da apresentação sobre Diego Rivera.

No cartaz da esquerda, os dados biográficos. No cartaz da direita, a leitura das obras selecionadas pelos alunos.

No total, cada turma apresentou doze trabalhos. Todos os alunos tiveram oportunidade de falar, muitos deles inclusive optaram por apresentar em espanhol. Dois ou três grupos tiveram certa dificuldade em resumir as informaçốes ou se ativeram a detalhes pouco representativos da vida do artista, mas, de modo geral, as apresentações foram ótimas. Os cartazes organizados pelos alunos foram expostos em painéis durante a Semana de Línguas do Colégio de Aplicação, ocorrida no mês de junho de 2008.

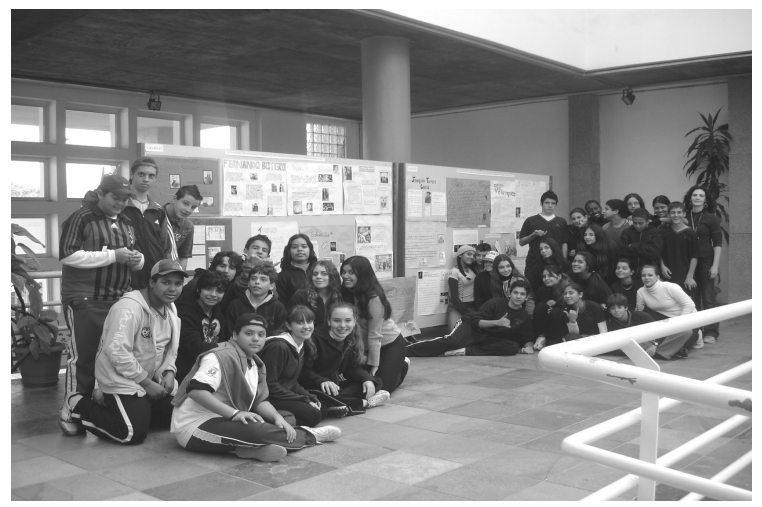

Fig. 2 - Alunos de uma das turmas de $8^{\mathrm{a}}$ série junto aos painéis em que foram expostos os cartazes, durante a Semana de Línguas (junho de 2008). 


\section{O que foi possível aprender com essa experiência?}

Essa experiência de ensino e aprendizagem usando biografias mostrou que as aulas de língua espanhola podem dar acesso a novos conhecimentos e informações superando a ideia de que aprender língua estrangeira é aprender bastante vocabulário e gramática.

Dentro de atividades que tinham como elemento chave o estudo de um gênero textual, foi possível explorar, refletir, discutir, compartilhar com os alunos e com professores de outras áreas de ensino, conhecimentos culturais, artísticos, literários.

Quanto aos alunos, acredito que o fato de as aulas terem propiciado diferentes momentos de reflexão conjunta, também os fez crescer coletivamente, já que toda a experiência exigiu atuação e participação ativa do grupo.

O intercâmbio constante de informações e sugestões com os(as) colegas de Artes (mesmo nos momentos em que houve troca de professores) enriqueceu significativamente as atividades propostas semanalmente nas aulas de espanhol. Era comum os alunos mencionarem que haviam ouvido o professor ou professora de Artes falar sobre tal pintor ou pintora, por exemplo. A ideia de incentivar os alunos a fazerem uma leitura pessoal das obras selecionadas para comporem a tarefa final foi outra proposta muito enriquecedora.

A experiência mostrou como é possível propiciar diferentes formas de aprender e ensinar utilizando as biografias na sala de aula. A apresentação da tarefa final, por parte dos alunos, mostrou que eles realmente estavam interessados e dispostos a compartilhar os seus novos conhecimentos com o grupo, arriscando-se inclusive a fazer toda a apresentação oral em espanhol. 


\section{Referências}

ALONSO, Encina. La programación y planificación de clases. In:

¿Cómo ser profesor y querer seguir siéndolo? Madrid: Edelsa, p. 163-180, 1999.

ALONSO, Talitha; CRISTOVÃO, Vera Lúcia Lopes. Biografias em inglês: uma abordagem do gênero sob a visão sócio-interacionista. In: CRISTOVÃO, Vera Lúcia Lopes. (Org.) Modelos didáticos de gênero: uma abordagem para o ensino de línguas. Londrina: UEL, p. 175-185, 2007.

BRONCKART, Jean-Paul. Atividade de linguagem, textos e discursos: por um interacionismo sócio-discursivo. $2^{\mathrm{a}}$ ed. São Paulo: Educ, 2003.

MACHADO, Anna Rachel. Apresentação. In: CRISTOVÃO, Vera Lúcia Lopes. Modelos didáticos de gênero: uma abordagem para o ensino de línguas. Londrina: UEL, p. VII-XI, 2007.

SCHNEUWLY, Bernard; DOLZ, Joaquim. Os gêneros escolares - das práticas de linguagem aos objetos de ensino. In: (Org.) Gêneros orais e escritos na escola. Campinas: Mercado de Letras, p. 71-91, 2004. 